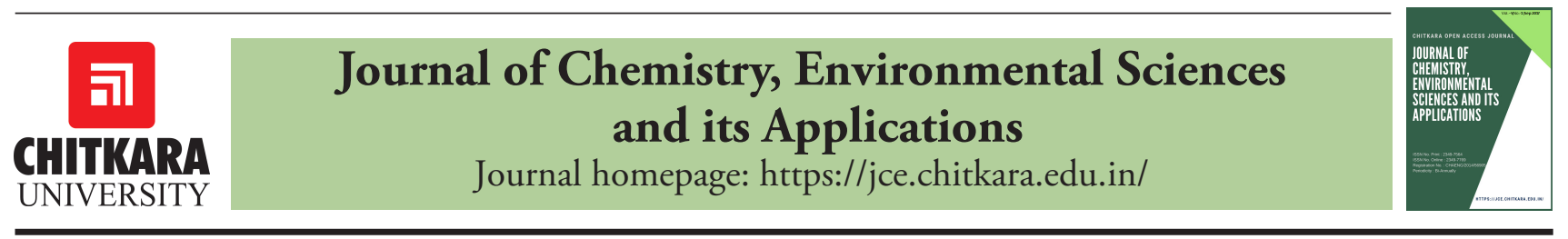

\title{
Maternal Health in Haryana: Evidences from NFHS
}

\author{
Ms Poonam Sandhir \\ Research Faculty, Population Research Centre, Centre for Research in Rural and Industrial Development 2A, Sector 19 A, 160019 Chandigarh \\ Email:poonam19s@yahoo.in
}

\section{ARTICLE INFORMATION}

Received: 21 July 2017

Revised: 05 August 2017

Accepted: 20 August 2017

Published Online: September 6, 2017

Keywords:

Maternal Health Care, NFHS, Women

Education

DOI: https://doi.org/10.15415/jce.2017.41005

\begin{abstract}
The paper is based on National Family Health Survey (NFHS) Haryana data collected during third and fourth round of survey. In terms of maternal health care indicators like ANC, IFA consumption, TT, assisted births, institutional births and PNC, Haryana performed better than India for parameters like TT, assisted deliveries and PNC; at par for IFA tablets and lower for ANC and institutional deliveries. Punjab was ahead of Haryana in terms of all these parameters. All these maternal health care indicators had a positive relationship with the raise in the educational level of the women. With the education the awareness level of women gets enhanced and they understand the importance of vital factors than their uneducated counterparts. Our policy planners and programme implementers should keep this important point well in mind that education is the key to easy eradication of all these problems and education of women will assist in achieving better results.
\end{abstract}

\section{Introduction}

In any human society, the care of mothers and children is the most vital social-health issue. Scientifically (in the preventive medicine), maternal and child health $(\mathrm{MCH})$ care has been defined as "the field of work related to the physical, mental and emotional health of women, immediately before, during and after the child birth of infant and young children", (R. S. Goyal, 1989). Maternal and Child Health/ Reproductive and Child Health $(\mathrm{MCH} / \mathrm{RCH})$ includes an effective antenatal, intra-natal and postnatal care for women and timely complete immunisation, provision of early detection and treatment of diseases and basic medical care when needed by the children.

Women who are the prime producer of life, on whom society depends upon for support and family health care; and the children who are our future and who will fulfil our dreams are the main targets of inequalities, injustices and inadequate health care in our society. The $\mathrm{MCH}$ services were started in India with the training of indigenous dais in 1866 by Miss Hewlett of the Church of England Zenana Mission, followed by other voluntary agencies, and of midwifery supervisors and Lady Health Visitors in 1918 (P. R. Dutt, 1993). After independence, with the UNICEF assistance, the $\mathrm{MCH}$ services gained importance. However poverty, illiteracy and associated social and cultural values are the major obstacles in this process. In order to lead our nation towards a healthy future, the government has been emphasizing the need for the safety of both the mother as well as the child, and to achieve this, special schemes have been formulated and launched for $\mathrm{RCH}$ care. $\mathrm{RCH}$ health service is one of the major programme of health care delivery system. The primary health centres (PHCs) are the main nuclei to render service to mother and child in rural areas through the network of sub-centres (SCs).

\section{Data Source}

The paper used the National Family Health Survey (NFHS) data collected during third and fourth round of survey. This was the first survey series to be started in India to collect dependable and up-to-date information on various population and health issues. Till now four surveys had been carried out smoothly under this NFHS series, at the all India level. The first one was in the year 1992-93 and the second NFHS was carried out in the year 1998-99. The third one was undertaken during the year 2005-06 and fourth one took place in 2015-16. Here data was used mainly from NFHS-4 and it was supported by NFHS-3.

\subsection{Objectives of the Study}

The main objective of the study paper was to look into mother health indicators of Haryana and affect of education on these parameters and make a comparative analysis with data from India and Punjab wherever required. 


\section{Profile of Haryana}

Haryana was born as a separate state on $1^{\text {st }}$ November 1966 after bifurcating the state of Punjab. Haryana became the $17^{\text {th }}$ state of India after separating the Hindi-speaking areas of the state of Punjab from the Punjabi-speaking ones. This state is located in the northern region of the Indian continent and is situated between $27^{\circ} 37^{\prime}$ to $30^{\circ} 35^{\prime}$ latitude and between $74^{\circ} 28^{\prime}$ to $77^{\circ} 36^{\prime}$ longitude. It is bordered in the west by Punjab, east by Uttar Pradesh, north by Himachal Pradesh and south by Rajasthan.

\subsection{Antenatal Care}

Antenatal care (ANC) means pregnancy related health care given to the pregnant woman by the doctor or health worker in a medical facility or at home prior to the childbirth. In the context of safe motherhood initiative proclaiming that all pregnant women must receive basic professional antenatal care, proper care during antenatal period are vital for the good quality health of the mother. Antenatal care includes, among others, the provision of iron and folic acid tablets, and tetanus toxoid (TT) injections. The information under this sub section was taken for the births in the last five years only. It is suggested that all pregnant women must be given antenatal care visits as they find and minimize dangers to life of both mother and child. Firstly the percentage of mothers who had at least four antenatal care visits for the last birth was looked into. During NFHS-3 data was collected for at least three ANC visits and it was found to be 59.2 per cent in 2005-06. In NFHS-4, about 45 per cent mothers claimed that they had at least four ANC visits.

Table 1. Maternity Care in Haryana.

\begin{tabular}{|c|c|c|c|c|c|c|c|c|c|}
\hline \multirow{2}{*}{$\begin{array}{l}\text { Maternity care }{ }^{*} \\
\text { (in percentage) }\end{array}$} & \multirow{2}{*}{$\begin{array}{l}\text { NFHS-4 } \\
(2015-16)\end{array}$} & \multicolumn{2}{|c|}{ Residence } & \multicolumn{5}{|l|}{ Education } & \multirow{2}{*}{$\begin{array}{l}\text { NFHS-3 } \\
(2005-06)\end{array}$} \\
\hline & & Urban & Rural & $\begin{array}{l}\text { No } \\
\text { schooling }\end{array}$ & $\begin{array}{l}<5 \text { years } \\
\text { complete }\end{array}$ & $\begin{array}{l}5-9 \text { years } \\
\text { complete }\end{array}$ & $\begin{array}{l}10-11 \\
\text { years } \\
\text { complete }\end{array}$ & $\begin{array}{l}12 \text { or } \\
\text { more years } \\
\text { complete }\end{array}$ & \\
\hline $\begin{array}{l}\text { Women who } \\
\text { had four or more } \\
\text { ANC visits during } \\
\text { pregnancy }\end{array}$ & 45.1 & 49.3 & 42.6 & 25.7 & 40.2 & 45.0 & 49.5 & 56.7 & $59.2^{* *}$ \\
\hline $\begin{array}{l}\text { Women who } \\
\text { consumed IFA for at } \\
\text { least } 100 \text { days during } \\
\text { pregnancy }\end{array}$ & 32.5 & 31.3 & 33.2 & 21.6 & 25.7 & 31.9 & 35.0 & 39.7 & 26.7@@ \\
\hline $\begin{array}{l}\text { Women who received } \\
\text { two or more TT } \\
\text { injections during the } \\
\text { pregnancy }\end{array}$ & 86.3 & 86.0 & 86.4 & 76.2 & 79.2 & 86.8 & 90.8 & 91.2 & 83.4 \\
\hline $\begin{array}{l}\text { Deliveries assisted by } \\
\text { health personnel @ }\end{array}$ & 84.7 & 85.0 & 84.5 & 67.4 & 69.2 & 86.9 & 92.0 & 94.8 & 48.9 \\
\hline Institutional births & 80.4 & 80.6 & 80.4 & 60.2 & 66.0 & 81.5 & 87.6 & 94.4 & 35.7 \\
\hline $\begin{array}{l}\text { Women who received } \\
\text { a postnatal checkup } \\
\text { within } 2 \text { days of birth }\end{array}$ & 70.8 & 69.8 & 71.4 & 56.9 & 62.1 & 70.7 & 73.0 & 80.1 & 55.9 \\
\hline
\end{tabular}

Note: - (i) * denotes that these figures are for last live birth in the five years preceding the survey.

(ii) @ Health personnel include doctor, ANM, nurse, midwife, LHV and other health personnel. If more than one person attended delivery then only the most qualified person is considered.

(iii) ${ }^{* *}$ denotes three or more ANC visits.

(iv)@ denotes at least 90 days.

Source: NFHS data.

These days more and more women are getting aware about availing ANC and its importance. However this percentage was much higher at the all India level (51.2 per cent) as well as in the neighboring state of Punjab (68.4 per cent). 
The percentage of mothers availing these antenatal visits was little higher in urban areas (49.3 per cent) than rural ones (42.6 per cent) in Haryana. Also, as the education level of the women increased from no schooling to 12 or more years completed their ANC visits during pregnancy also increased from 25.7 per cent to 56.7 per cent steadily. Studies have revealed that usage of mother and child health $(\mathrm{MCH})$ services gets influenced by women's education. Another factor having its influence is the place of residence (urban/ rural) (Ray et al. 1984 and Barlow and Diop 1995).

In NFHS-4 some information was collected in different pattern compared to NFHS-3. It was about mothers who consumed iron and folic acid (IFA) tablets during pregnancy. For NFHS-3 it looked into data for women who consumed IFA for at least 90 days when they were pregnant with their last child. However during NFHS- 4 this data was captured for at least 100 days. In spite of such a large and extensive health set up and government's efforts in this direction only 32.5 per cent women had consumed IFA tablets for 100 or more days at the time of last pregnancy. The all India figures were almost at par at 30.3 per cent and Punjab performed better at 42.6 per cent. There was a difference of about two per cent in consumption of this tablet in rural (33.2 per cent) and urban (31.3 per cent) areas. The level of education had direct influence on the consumption of IFA tablets. It was more among the educated women. The consumption rate improved with the level of education i.e. 21.3 per cent for no schooling women, 25.7 per cent for women who had gone to school for less than five years, 31.9 per cent for those who had studied for five to nine years, 35 per cent for ten or eleven years completed and 39.7 per cent for the women who had completed twelve or more years of education. Preventable neonatal tetanus is most common when the delivery takes place in an unhygienic environment in rural areas, where expert medical help is rarely available. Two doses of tetanus toxoid (TT) vaccine, given one month apart during early pregnancy are nearly 100 percent effective in preventing tetanus among the newborns and their mothers.

For Haryana, the percentage for women who received two or more TT injections during the pregnancy enhanced marginally from NFHS-3 (83.4 per cent) to NFHS4 (86.3 per cent). Not much variation was observed in corresponding figures for India and Punjab. National level percentage was three points lower at 83 per cent and Punjab figures were three points higher at 89 per cent. Women receiving two or more TT injections were same at about 85 per cent at both rural and urban level. The acceptance of TT injections increased gradually with increase in years of education completed. It was 76.2 per cent for women with no schooling, 79.2 per cent for less than five years of schooling, 86.8 per cent for five to nine years of schooling,
90.8 per cent for ten to eleven years and 91.2 per cent for twelve or more years of education completed.

\subsection{Institutional/Assisted Births}

As per NFHS Haryana, the percentage of women whose births were assisted by doctor/ nurse/Lady Health Visitor (LHV)/Auxiliary Nurse Midwife (ANM)/other health personnel was much higher (84.7 per cent) in fourth round as compared to third round ( 48.9 per cent). This indicates that women in Haryana are getting better healthcare facilities then previous times. Haryana's performance was three per cent better than India (81.4 per cent) but it was ten per cent lower than Punjab (94.1 per cent). Assisted births were almost comparable in urban ( 85 per cent) and rural 84.5 per cent) areas. The level of awareness that safety of mother and child is more in assisted births compared to unassisted births is linked with the education of women. More educated women are aware about this fact. NFHS4 Haryana gave that 67.4 per cent births of the illiterate women were assisted births. On the other hand doctor/ nurse/LHV/ANM/other health personnel assisted 94.8 per cent of the births of the women with at least twelve years of education.

Institutional delivery i.e. delivering a child in a medical facility under the overall supervision of trained and capable health people surely reduces the chances of infant and maternal mortality. Many programmes like Child Survival and Safe Motherhood (CSSM) and the Reproductive and Child Health $(\mathrm{RCH})$ programmes have already worked in this direction. Government's dedication in this path is revealed in the goals of the National Population Policy (NPP), National Health Policy (NHP) and National Rural Health Mission (NRHM) launched on 12 $2^{\text {th }}$ April 2005. Now NRHM has been replaced by National Health Mission (NHM). The NHM has safe motherhood intervention programmes like Janani Suraksha Yojana (JSY) and Janani Shishu Suraksha Karyakaram (JSSK). The objectives of these programmes are to reduce Maternal Mortality Rate (MMR) and Neonatal Mortality Rate (NMR) by promotion of institutional deliveries.

Institutional births in Haryana also indicate a very positive trend from a mere 35.7 per cent in NFHS-3 to 80.4 per cent in NFHS-4, which still has room for improvement. These figures were close to national average of 78.9 per cent. However the neighbouring state of Punjab was performing better at 90.5 per cent. The percentage of institutional deliveries was alike in urban (80.6 per cent) and rural (80.4 per cent) women. May be the effort of grass root level health workers and lure of benefits of institutional deliveries under various programmes have resulted in these positive outcomes in rural areas. Data revealed that the preference 


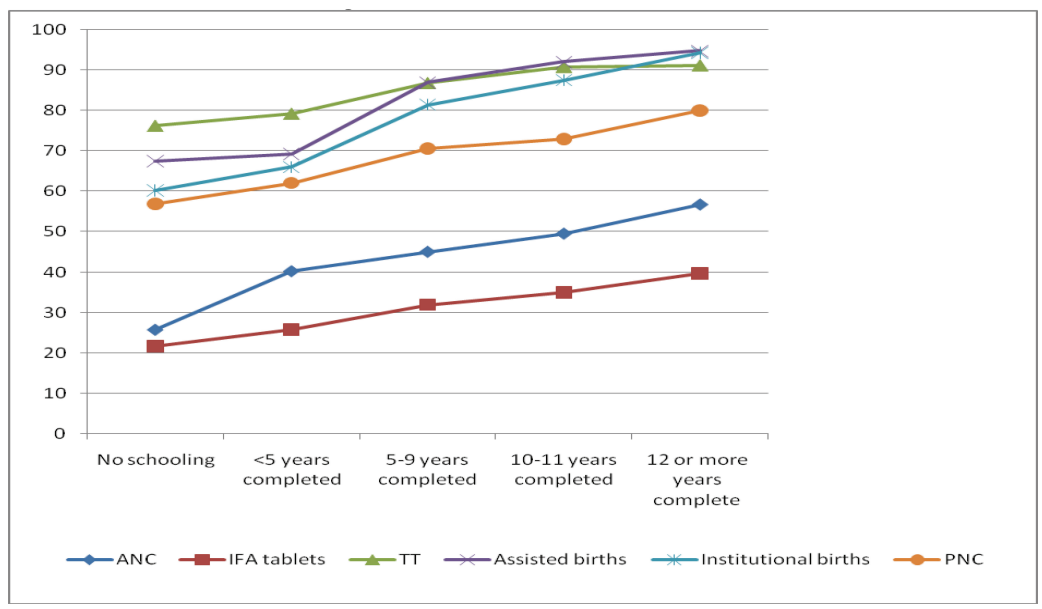

Figure 1. Maternity Care and Women Education.

for institutional deliveries was more among the educated women than the less educated ones. There was a difference of 24 per cent in acceptance of institutional births among not educated women (60.2 per cent) and women who have completed at least twelve years education (94.4 per cent). In fact, the volume of deliveries in the non-institutional sector is a sign of economic backwardness and low benchmark of health position in the society.

\subsection{Postnatal Care}

The postnatal care (PNC) is the care offered during initial few weeks to the mother and child, immediately after the childbirth. This care helps in dealing with any complications developing after the birth and it sees that the course of recovery after the birth is on the expected lines. One other benefit is that it helps in finding answers to the mothers queries regarding her and child's well being. The percentage of mothers who received postnatal care from doctor/nurse/ LHV/ANM/other health personnel within two days of delivery for their last birth was 70.8 per cent in the State. In NFHS-3 these services were received by 55.9 per cent of surveyed women. Here also Haryana performed better than India (65.1 per cent). Like antenatal care, postnatal care was also received more by women in the neighbouring state of Punjab (89.3 per cent). The educated women received the postnatal care more than their counterparts. As the education increased from no education $(56.9$ per cent) to twelve or more years of education completed (80.1 per cent) the acceptance of postnatal care also increased gradually.

Interestingly, a common feature among all the points covered under maternity care in the table given above was that all the parameters have a positive relationship with the educational level of the women. As the educational level of the women increased, it enhanced the acceptance of ANC (i.e. at least four antenatal care visits for the last birth), IFA (i.e. consumption of 100 or more IFA tablets at the time of last pregnancy), TT (at least two TT injections during last pregnancy), assisted births (i.e. births assisted by a doctor/ nurse/LHV/ANM/other health personnel), institutional births (i.e. births conducted at a health institute) and PNC (i.e. received PNC care from a doctor/nurse/LHV/ANM/ other health personnel within two days of delivery).

The Figure 1 depicted that for all the six parameters increase was clearly visible. Actually with the education the awareness level of women gets enhanced and they understand the importance of all these vital factors and role played by them in the safety of mother and child much better than the uneducated counterparts. This point should be kept well in mind while making different policies and programmes that education is the key to easy eradication of all these problems.

\section{Conclusions}

In terms of maternal health care indicators like ANC, IFA consumption, TT, assisted births, institutional births and PNC, Haryana has improved from NFHS-3 to NFHS4. When compared with India and neighbouring state of Punjab, Haryana performed better than India for parameters like TT, assisted deliveries and PNC; at par for IFA tablets and lower for ANC and institutional deliveries. Punjab was ahead of Haryana in terms of all these parameters. A common characteristic for these maternal health care indicators (ANC, IFA consumption, TT, assisted births, institutional births and $\mathrm{PNC}$ ) was that they all had a positive relationship with the increase in the educational level of the women. The results show that education is very important in today's world and no body should be deprived of it. With the education the awareness level of women gets enhanced and they understand the importance of vital factors than their uneducated counterparts. So our schemes and 
programmes in the near future should target more on less educated women in this direction. Our policy planners and programme implementers should keep this important point well in mind that education is the key to easy eradication of all these problems and education of women will assist in achieving better results.

\section{References}

Dutt, P. R. (1993). Primary Health Care Volume 2, Mother and Child, Immunization, Family Planning. The Gandhigram Institute of Rural Health and Family Welfare Trust.

Goyal, R. S. (1989). Maternal and Child Health Care Practices. A Socio-Demographic Study of Rural Areas in Himachal Pradesh. Population Research Centre, Panjab University, Chandigarh.

International Institute for Population Sciences (IIPS) and ICF. 2017. National Family Health Survey (NFHS-4), 2015-16: India. Mumbai: IIPS.

International Institute for Population Sciences (IIPS) and ICF. 2017. National Family Health Survey (NFHS-4), India, 2015-16: Punjab. Mumbai: IIPS.
International Institute for Population Sciences (IIPS) and ICF. 2017. National Family Health Survey (NFHS-4), India, 2015-16: Haryana. Mumbai: IIPS.

International Institute for Population Sciences (IIPS) and Macro International. (2008). National Family Health Survey (NFHS-3), India, 2005-06: Haryana. Mumbai: IIPS.

K. S. Sugathan, Vinod Mishra and Robert D. Retherford. (2001). Promoting Institutional Deliveries in Rural India: The Role of Antenatal-Care Services. National Family Health Survey Subject Reports, Number 20.

Prakashan, Padma. (1993). New Approach to Women's Health Care means to an End? Economic and Political Weekly. Vol.28, No.51. pp: 2783-2786.

R. Barlow and F. Diop. (1995). Increasing the Utilization of Cost-effective Health Services through Changes in Demand. Health Policy and Planning, 10, 3. 284-295.

S. K. Ray, B. B. Mukhopodhyay, R. Das, M. M. Ganguly, A. Maidal and S. C. Roy. (1984). Extent of Utilization of Maternal Health Care Services of PHC by Families of a Rural Area. Indian Journal of Public Health, 28, 3. $122-127$. 